\title{
Effects of Functional Instruction on Types of Achievement in Reading Narrative Texts
}

\author{
Aldo Bazán ${ }^{1}$, Dorle Ramos ${ }^{2}$, Mónica Dávila ${ }^{2}$, Néstor Velarde ${ }^{1} \&$ Maricel Rivera $^{2}$ \\ ${ }^{1}$ Autonomous University of the State of Morelos, Transdisciplinary Research Center in Psychology, Mexico \\ ${ }^{2}$ Technological Institute of Sonora, Education Department, Mexico \\ Correspondence: Aldo Bazán, Autonomous University of the State of Morelos, Transdisciplinary Research Center \\ in Psychology, Mexico
}

Received: July 13, 2018

Accepted: August 8, 2018

Online Published: August 24, 2018

doi:10.5539/ijps.v10n3p80

URL: https://doi.org/10.5539/ijps.v10n3p80

This research had the support of the National Council of Science and Technology of Mexico, CONACyT, Project No. 151981.

\begin{abstract}
Seventeen first-year Secondary School students with low levels of reading comprehension of mystery and horror stories, received training during two weeks in 50-minutes daily sessions. The structural planning was sequentially organized, in four types of teaching - learning situations going from lower to higher level of complexity. The instruction was implemented in accordance with four types of achievement levels: linked to the object, linked to the situation, non-linked to the operation, and non-linked to present situation. The results throughout the intervention revealed that in the two first levels (object-linked and operation-linked), average scores above $90 \%$ of achievement were obtained. In the two operation - non-linked levels (particular and present situation non-linked), averages scores between 73 and $76 \%$ of achievement were reached. Likewise, a significant change $(p=0.005)$ was found in a previous and post-evaluation of a school curricular unit for the group intervention, with no significant differences for the control group.
\end{abstract}

Keywords: reading comprehension, Functional analysis, Learning, interbehaviorism

\section{Introduction}

The purpose of this study was to elaborate and apply an intervention under the interbehavioral psychology approach to the reading comprehension of mystery and horror stories. The participants of the study were first-year secondary school students who had demonstrated low levels of reading comprehension the previous academic year (SEP, 2011).

In the study of reading comprehension there is a predominance of cognitive models, which in general are conceived as a process not directly observable and which in turn consists of multiple cognitive processes. To understand a text, it is essential that the reader can decode linguistic units and construct a mental representation of the text. Subsequently reading can access this mental representation to remember the information in the text, to answer questions about the text, or to apply the knowledge obtained from the text (Keenan, Betjemann, \& Olson, 2008). According to Pearson and Cervetti (2017), these cognitive models are contextually impoverished and do not take into account diversity.

More naturalistic approaches to reading comprehension describe a relationship between the reader and the text, a way of behaving depending on the characteristics of the text and the demands and criteria imposed by the text, and / or what the reader is asked to do when reading or after having read it, and according to various levels of capacity or functional aptitude required in a specific field of interaction.

According to Wittgeinstein (1997) understanding (or comprehension) refers to a form of human behavior and not a state of consciousness (feeling or sensation), such as feeling pain or hearing a sound, "that someone really understood or it is not something that is determined from what you do later or from the explanation that we could request" (Wittgeinstein, 1997, p.40). Likewise, Ryle (2005) points out that when we characterize people through mental predicates, we describe the ways in which such people behave publicly, and not hidden events or processes. 
For Ryle, to comprehend is a form of knowing how to do, and not a form of inferring or guessing hidden processes (in texts, acts or words).

Under an interbehavioral perspective in psychology, Kantor and Smith (1975) consider that understanding (comprehension) something or an event, implies not only the ability to evaluate or analyze it, but also to connect with the origins, development and future change of this object or event. Thus, understanding (comprehension) is a behavioral component of interactions with environmental conditions. It is a naturalistic occurrence tied to the adjustments or adaptations of the individual in a specific situation (Kantor, 1983).

Carpio, Pacheco, Flores and Canales (2000) contend that understanding is not something that an individual does, but rather a function or relationship, in which the individuals and his activities become an integral part. This function or relationship includes three elements: "the subject who understands, that which is understood and the minimum conditions necessary for the relationship between these two elements to be established in a way that we call understanding" (Carpio, et al., 2000, p. 7). Therefore, comprehension is a term of achievement, which relates to particular behavior in a particular circumstance.

Fuentes and Ribes (2001) point out that reading comprehension consists in behaving in an appropriate manner according to the functional characteristics of the text (as a modality that depends functionally on the text). It also consists of an adjustment to different performance criteria (skills levels that configure efficiency criteria that require qualitatively different and hierarchically complex interactions) and depends on four factors:

...the functional characteristics of the text, the circumstances in which the reader interacts with the text, the functional competences of the reader to interact at a certain level or another with a text with specific characteristics, and the comprehensive performance criteria established to respond effectively to the text and its demands. (Fuentes \& Ribes, 2001, pp. 184).

On the other hand, Arroyo et al. (2005) affirm that the term reading comprehension describes a particular way in which the reader adjusts his behavior to the circumstances and the text in an effective and pertinent way. The fundamental situation that mediates the interaction between the reader and the text is the criterion of adjustment that is imposed:

The adjustment criteria, when delimiting the demand imposed in a reading situation (demand that can be imposed by another person or by the same reader), becomes the structuring element of the interaction, so that the use of such criteria makes possible evaluate the functional level in which the behavior of the reader is structured, by its correspondence with the imposed demand (Arroyo, Canales, Morales, Silva, \& Carpio, 2007, p.33).

For Ribes, Ibáñez and Pérez (2014), comprehension is an achievement term that specifies a result, but not actions, and understanding is a term that corresponds to episodic categories. The latter outlines the circumstances in which the relationship between a performance and an achievement are described; however, "comprehension, as an achievement, always presupposes understanding as an episode. They are 'symbiotic' categories, to put it in some way: one cannot be applied without presupposing the other." (Ribes et al, 2014, p.102).

Under this interbehavioral perspective, reading comprehension implies the functional possibility that the reader can respond effectively in reading tasks and varied situations, according to demands in more complex functional levels of behavior, constituting reading, a key condition for the student to develop skills related to other school subjects (Guevara, Cárdenas, \& Reyes, 2015). Likewise, Irigoyen, Acuña and Jiménez (2017) pointed out that the term comprehension describes the student's achievements with respect to a criterion and the circumstances in which it may or may not occur as probability; circumstance in which the mediation on the part of the teacher fulfills a substantial function in the identification and fulfillment of the adjustment or achievement criteria specified in an academic curriculum.

Applied to the theme of this article, to understand a text in curricular learning environments, it is necessary that the learner go through episodes or situations that make it possible to comprehend. It must be based on arrangements and conditions that regulate the relationship between performance and achievement. In this sense, these conditions of comprehensive learning are only an element of the acquisition and development of competences - as facilitating stages of the acquisition of competences -, which are identified from linguistic acts "which result in an achievement in a given situation, based on an explicit functional criterion" (Ribes et al., 2014 p.109).

\subsection{Skills Planning and Functional Education}

Ribes (2008) proposed a structural model of skills planning in basic education and later supported his prototype in an integral perspective of the concept of competence in a model of psychological development in education (Ribes, 2011). Some relevant aspects of this model for planning and learning interaction for basic education are: 
1. A statement of the logical conceptual inconsistencies of the use of the term competence for teaching and learning and its reconceptualization.

2. Lesson planning that focuses on interaction and the learner psychological development of aptitude and skills at hierarchical and functionally more complex and inclusive levels (Ribes \& López, 1985).

3. The structural model implied establishing criteria for domains of both disciplinary knowledge and domains of life (or useful knowledge in the life of the human being, in a perspective of education for life), and combinations of expected domains (transversal competences).

4. The model allowed the teacher to take into account the elements of the psychological field in the teaching planning (Kantor \& Smith, 1975). These factors are interrelated and influenced and shape their interactive nature, depending on the levels of functional detachment that shall be structured (Ribes, 1990).

The model of skills planning in basic education that Ribes presented is focused on the learner, in which criteria of achievement are set and interaction situations are established according to the levels of functional aptitude. These criteria, according to author, cover the five levels of functional aptitude described by Ribes and López (1985) and by Ribes (1990) for the analysis of behavioral competences.

Following this model, the teacher can plan the teaching interaction starting from: a) the specification of teaching-learning units and subunits; b) the ways in which the learning interactions and the student actions involved in such educational sessions will be established (recognizing, executing, selecting, imagining, theorizing); c) materials and places. They can also specify the achievement that students are expected to obtain at the end of a session or sequence of sessions, according to the following criteria: linked to the object, linked to operation, non-linked to operation, non-linked to the present situation and non-linked to the concrete situation.

Table 1 shows two axes of the learning process based on competences, the first referred to the learning activities and the second, referred to the type of achievement that the learner must achieve. These axes suggest the types of achievement students can reach. For example, in understanding narrative texts, this will depend both on the specification of achievement criteria and on the type of learning activities during learning interactions. For example, proposing explanations, establishing new relationships and definitions or classifications from a read text should be developed in teaching situations that allow students to read texts establishing relationships, arguing and making analysis of consequences, and other activities of foundation and theorization.

Table 1. Learning activities and types of achievement

\begin{tabular}{ll}
\hline $\begin{array}{l}\text { Axes of learning activities during the } \\
\text { teaching interaction }\end{array}$ & TYPE OF ACHIEVEMENT \\
\hline RECOGNIZING & LINKED TO OBJECT \\
Attending, identifying, anticipating & $\begin{array}{l}\text { Name, mark in diagram or map, qualify statements as true or } \\
\text { false, paraphrase }\end{array}$
\end{tabular}

\section{EXECUTING}

Pointing, experimenting, locating

\section{SELECTING}

Ordering, comparing, modifying approach

\section{IMAGINING}

Relating in type, time, place,

Acting 'as if'

\section{THEORIZING}

Establishing relations, effect, consequences

\section{LINKED TO OPERATION}

Building, tracing, applying procedure, describing, drawing, answering direct questions, summarizing

\section{NON-LINKED TO OPERATION}

Sorting, identifying or making changes, selecting

\section{NON-LINKED TO PRESENT SITUATION}

Exemplifying, interpreting past or current absent situations, proposing new artifacts, uses or procedures

\section{NON-LINKED TO CONCRETE SITUATION}

Arguing, hypothesizing, proposing explanations, establishing new relationships, definitions or classifications

Source: Table elaborated taking central elements of the "Representation of the learning process based on competencies" by Ribes (2008, Figure 3). 
Various studies have been carried out on the development of competences in basic and upper secondary education oriented in the interbehavioral perspective.

Bazán (2013), adapted this structural model of skills planning and developed a didactic planning proposal for the functional teaching of the production of texts of a curricular block of 5th grade. The included thematic units in which the student must meet certain criteria of achievement in adjustment to the levels of functional aptitude stated in the teaching planning, specifying the general achievement, the achievements for each thematic sub unit, the five functional criteria of achievement (linked: to object and to the operation,; non-linked to: operation, present situation and of concrete situation), the situations and the activities included, among others.

Similarly, Rodríguez-Ramírez and Rodríguez-Pérez (2014) have proposed and developed a methodology to analyze situations of skills-based education from the theoretical interbehavioral approach in the teaching of biology at the beginning of upper secondary education (high school), in a public institution of the City of Guadalajara (México). In the one hand, the analysis method allowed to describe functionally the teaching competence 'structuring relevant teaching-learning situations'. On the other hand, it allowed to describe the didactic discourse and the structuring of the didactic interactions based on the established achievement criteria, and the actions of the teacher and the students to fulfill these achievements.

Moreno, Bazán, Pacheco and Irigoyen (2017) conducted a research with students in last semester of teacher training school pursuing a degree in Spanish. They implemented experimentally an intervention program in accordance with the structural model of skills planning, developing in trainee teachers, the skills to design plans for a curricular block of the subject of Spanish in the second year of secondary school, also, according to the structural model of planning with the interbehavioral approach.

Likewise, Velarde and Bazán (2017) implemented an intervention program to develop reading comprehension skills of a group of sixth grade primary school students, with low achievement indicators at the end of the $\mathrm{V}$ curricular block, in "reading and writing poems to share". A pre- and post-treatment analysis showed a significant increase in the execution of the reading activities. Also, the tests at the end of the instructional situations according to each linkage and non-linkage criterion and specified achievement, showed that the development of the competence to understand literary texts (poems) are configured into a hierarchy according to the characteristics that functionally correspond to the levels of functional aptitude and their achievement criteria: linked to object, linked to operation, non-linked to operation, non-linked to present situation and non-linked to concrete situation.

Other studies under the interbehavioral perspective have focused on the development of skills to understand texts of a different nature, for example, literary texts, natural sciences and arithmetic. Cárdenas and Guevara (2013) reported that arrangements in levels of referential substitution interaction included in teaching situations, allow greater development of reading comprehension, both literary topics, and natural sciences, in first year secondary school. Tamayo and Pulido (2015) conducted experiments with sixth grade students to test the effect of exposure to five skills levels of different complexity on the linguistic habilitation between complementary reactive-active modes in the learning of the commutative property of the sum. They found that, the read-write modes generated a greater number of cases of linguistic habilitation.

\subsection{Purpose of This Study}

This study had two main purposes. The first, to assess the effect of a training program focused on the learner. This was conducted according to the specification of achievement criteria and activities organized into four levels of linkage / non-linkage with respect to instructional referents, on group performance before and after in tasks of reading mystery and horror stories (curricular content of the 2nd block of sixth grade) and contrasting it with a control group (control).

The second purpose was to develop in each of the students, four types of achievement organized into a hierarchy (linked to object, linked to operation, non-linked to operation and non-linked to present situation) for the understanding of narrative texts of a curricular unit (mystery and horror stories). The latter considered an effect of the functional teaching in four levels of interaction with the texts.

The classroom teaching was done under the perspective of interconductual psychology, in accordance with the model of structural planning and the learning process based on skills proposed by Ribes (2008) depending on the type of linkage and non-linkage to the subject or reference of instruction, and attached to the structural planning that he specified among the most relevant aspects:

1. The learning situation,

2. The actions of the teacher and the student in the teaching-learning situations (recognizing, executing, selecting and imagining), 
3. Achievements identified from the behavior of the student as correspondence at various levels and compliance with criteria (linked to object, linked to operation, non-linked to operation and non-linked to present situation), and

4. The objects, materials and events with which the student had to interact. They should be mediated by the teacher, in correspondence with the criteria of functional aptitude and achievements, depending on their proposed linkage and non-linkage.

\section{Method}

\subsection{Design}

For the first objective of the study, a quasi-experimental design was used, with a control group without treatment and with pre-test / post-test. The intervention group (experimental) received an interbehavioral program for two weeks, in four types of achievement, organized from minor to greater functional complexity: Linked to operation, Non-linked to operation, Non-linked to present situation, and Non-linked to concrete situation. The control group (control) did not receive any treatment. Both groups were evaluated before and after the intervention, with the same two tasks of reading stories of mystery and horror, corresponding to the curricular unit of block II of the Spanish subject, sixth grade of primary school.

For the second objective, a pre-experimental design with a single group was used, with individual measurements in the four levels of intervention organized into a hierarchy: Linked to operation, Non-linked to operation, Non-linked to present situation, and Non-linked to concrete situation.

\subsection{Participants}

This study involved 34 students from 11 to 12 years old, from two school groups (two sections) of the first year of secondary school of a public school in the State of Sonora, Mexico, with low marginality index. The choice of the secondary school was at convenience because of the facilities provided by its governing body.

Out of a total of six first-year sections or groups, two sections, Group B and Group C were chosen at random. The two groups selected were randomly assigned to one of the conditions, intervention group (experimental) or control group (control), and in each of the groups 7 men and 10 women participated.

In order to identify the homogeneity of the variances before making the comparisons between the groups, Levene's test was applied to the data in the pre-evaluation and the result was a value of $F=2.80$ and value of significance $=.10$. The data support the assumption of homogeneity of the variances between both groups, before starting the intervention.

\subsection{Ethical Considerations}

The study was conducted according to ethical criteria in research, with special attention being devoted to the signing of informed consent by parents, the director and teachers of the two groups, and the agreement of voluntary participation of children. In addition, confidentiality and data protection were ensured and it was explained to all those involved that the information would be used for research purposes and their performances and responses would be completely anonymous and that everyone had the right to withdraw from the study at the time they wanted, if so decided.

\subsection{Instruments}

For the pre and post assessment of the expected learning "Identify the characteristics of mystery or horror stories: structure, style, characters and scenario" in the sixth grade of primary school (SEP, 2011, Agreement 592, p.303), two exercises of the questionnaire for the evaluation of reading comprehension and text production for the sixth grade of Bazán, Barrera and Vega (2013) were used. Table 2 shows the indicators, criteria and evaluation of the answers in a range from 0 to 4 in each of the two texts. 
Table 2. Evaluation of comprehension of two narrative texts in sixth grade of primary level, Block II Tales of mystery or horror.

Indicators Criteria Values

Identify the structure of the text, a) Identify the characters in the story. 0 . Does not perform the exercise or main characters, setting and the b) Select the characteristics of mystery does not meet any of the criteria. characteristics of a horror and or horror stories. 1. Meets one of the criteria. mystery story

c) Choose correctly the structure of the 2. Meets two criteria. story: presentation, climax and 3 . Meets three criteria. dénouement.

d) Infers the scenario where the story 4. Meets all the criteria. unfolds

For the intervention, eight teaching-learning through skills sessions about "characteristics of mystery or horror stories" were planned, that correspond to the second block of the subject of Spanish for sixth grade of primary school according to the plan and curriculum and the sixth grade primary textbook in force in the 2014-2015 cycle.

This planning emphasized the learning of reading comprehension according to the learning conditions and the criteria corresponding to the expected level of achievement, considering the first four achievements indicated in Table 1 . The activity to discuss modifications or individual or group proposals was added at level 4 (non-linked to the present situation) because arguing on its own does not correspond properly with the last level of achievement (non-linked to concrete situation). In Appendix 1 some of the instructional activities that were carried out in the intervention are shown. Likewise, a manual was prepared with the instructional and evaluation exercises.

The first level of teaching-learning included attention activities, identification and anticipation regarding the elements, characters in the texts, and was aimed at achievement linked to the object, which involves actions such as, naming, marking in diagram or map, qualifying affirmations such as true or false, paraphrasing, etc.

The second level implies that the student interacts with the mystery and horror stories, executing (pointing, experimenting, locating), which includes the student's actions to construct, trace, apply procedures, describe, draw, answer direct questions, summarize (link to operation).

The third level includes situations in which the student interacts with the narrative texts, selecting: Sorting, comparing, modifying criteria. At this level the student must be able to, classify, identify or make changes, select (non-linked to operation).

The fourth level comprehend reading activities in which the students establishes relationships in type, time and place, and must be able to exemplify, propose new ways of presenting a text (from horror to mystery or from mystery to horror), interpret actions and situations based on the characters and argue their conclusions and ideas (non-linked to present situation / non-linked to concrete situation).

Both the planning (instructional design) and the manual of exercises and work materials, were validated by three psychologists with interbehavioral orientation and experience in learning planning, and by two specialists with a master's degree in educational sciences, teaching experience and instructional design.

\subsection{Procedure}

As a pre-test, both the 17 students of the intervention group and the 17 students of the control group were subjected to a 6th Grade Primary Level evaluation of curricular achievement in reading stories of mystery or horror. In the same way, this evaluation was applied after the intervention.

Subsequently, the eight sessions instruction program of 50 minutes each one, was applied to the intervention group over two weeks. These sessions were implemented at the time that the group had to take the subject of Spanish in the first year of secondary school, having therefore a varied schedule (some sessions were in the first hour of classes, others after recess and others in the last hour of classes) and always in the classroom corresponding to this subject.

The instruction was developed by a graduate of Educational Sciences, trained in the theoretical foundations of interbehavioral psychology, the skills planning model proposed by Ribes (2008); and has collaborated in the planning of the program. It is worth mentioning that the Spanish teacher of the first year of secondary school was not present at the work sessions. 
Each level of achievement was developed in two sessions, at the end of the second session in each level, the instructor carried out an application activity to evaluate the achievement and gave feedback to the students.

\section{Data Analysis}

For data analysis purposes of the pre and post evaluation applied to the control and experimental groups, the scores obtained in each text (from 0 to 4 ) were summed and converted into percentage of achievement in a range of $0=$ $0 \%$ and $8=100 \%$.

For the analysis of data of the process evaluation in the experimental group, in each of the four levels of achievement a scale was used that goes from 0 to 100 , according to the fulfillment of established criteria in the evaluation tasks in each achievement.

To make the comparison between the groups in the previous and subsequent evaluations and for the before and after intra-group comparisons, the student's $t$ test was used for paired samples using the statistical package SPSS Statistical Package for the Social Sciences, version 23.

\section{Results}

The results derived from the study are described below, starting with the assumptions of homogeneity of the variances as a pre-requisite to be able to apply the comparison test. Later, the comparison of the means between the groups before the intervention, is presented. Once the comparison between the groups without intervention was made, the comparison after the treatment to the experimental group was established. Finally the percentages of the performance of the participants during the intervention program are presented.

Table 3 shows the fulfillment of the assumption of homoscedasticity or homogeneity of the variances, since equal variances are assumed between the means of the groups prior to the application of the intervention. Henceforth it is possible to establish comparisons once the intervention program has been carried out.

Table 3. Checking of the assumption of homogeneity of the variances before making the comparison between the groups.

\begin{tabular}{ll}
\hline Levene's Test & Sig. \\
\hline 2.803 & .104
\end{tabular}

Note: equal variances are assumed between the groups, which allows to establish comparisons between the groups.

In the upper part of table 4, the comparison between the groups prior to the application of the intervention program with a t-test for independent samples is presented. In the lower part of table 4 the comparison of means between groups in the post-intervention evaluation to the experimental group is shown.

Table 4. Comparison of means between groups, before and after the intervention

\begin{tabular}{llllll}
\hline \multicolumn{5}{c}{ Comparison of means between groups prior to intervention } \\
\hline Groups & $\mathbf{M}$ & $\mathbf{N}$ & $\mathbf{S E}$ & $\mathbf{t}$ & Sig. \\
\hline B (Control) & $\mathbf{5 2 . 9 4}$ & 17 & 11.29 & .284 & .779 \\
\cline { 1 - 4 } C (Experimental) & $\mathbf{5 1 . 4 7}$ & 17 & 18.15 & \\
\hline
\end{tabular}

Note: There are no significant differences between group means, $p=<.05$

\begin{tabular}{llllll}
\hline \multicolumn{2}{l}{ Comparison of means between groups after the intervention } & & \\
Groups & $\mathbf{M}$ & $\mathbf{N}$ & $\mathbf{S E}$ & $\mathbf{t}$ & Sig. \\
\hline B (Control) & $\mathbf{5 5 . 1 4}$ & 17 & 7.72 & -3.47 & .002 \\
\hline C (Experimental) & $\mathbf{6 6 . 9 1}$ & 17 & 11.64 & &
\end{tabular}

Note: There are no significant differences between group means, $\mathrm{p}=<.05$

Table 5 shows the intra-group comparison before and after the intervention, in the evaluation of the curricular achievement in reading mystery-horror stories corresponding to the 6th grade of primary school, for each text and the total average. Likewise, a significant change can be observed in the intervention group (experimental) with respect to the pre and post evaluation $(\mathrm{p}=0.05)$, while in the comparison group the change was not significant. 
Table 5. Comparison between groups in evaluation of curricular achievement in reading mystery - horror stories before and after the intervention

\begin{tabular}{llllll}
\hline \multicolumn{1}{l}{ Test of paired samples } & & & & \\
\hline Groups & Media & $\mathrm{N}$ & $\mathrm{SE}$ & $\mathrm{t}$ & sig. \\
\hline B (Control) & 52.94 & 17 & 11.03 & -.824 & .422 \\
& 55.14 & & & & \\
\hline C (experimental) & 51.47 & 17 & 19.53 & -3.260 & $\mathbf{. 0 0 5}$ \\
& 66.91 & & & & \\
\hline
\end{tabular}

Note: The difference between the means of the experimental group was significant in comparison with the difference of means of the control group, $p=<.05$.

Figure 1 shows the individual averages in the pre and post evaluation of the control group students. In twelve students there were no changes in their performance, three students increased their performance in the post evaluation and two students lowered their percentage of correct answers.

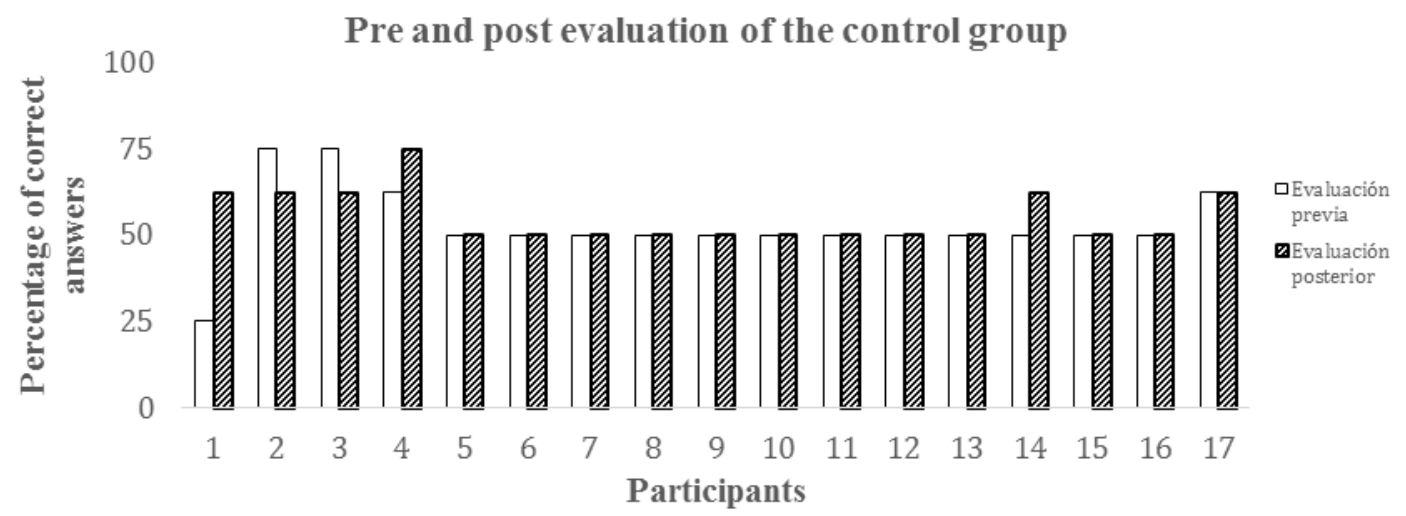

Figure 1. Percentages of correct answers of the control group participants in the previous and subsequent evaluations.

Figure 2 shows the comparison of the individual results in the pre and post evaluation of the students of the experimental group. It is observed that eleven participants increased the average performance in the post evaluation, five participants maintained the same average in both evaluations and one student had lower performance in the post evaluation.

\section{Previous and subsequent evaluation of the experimental group}

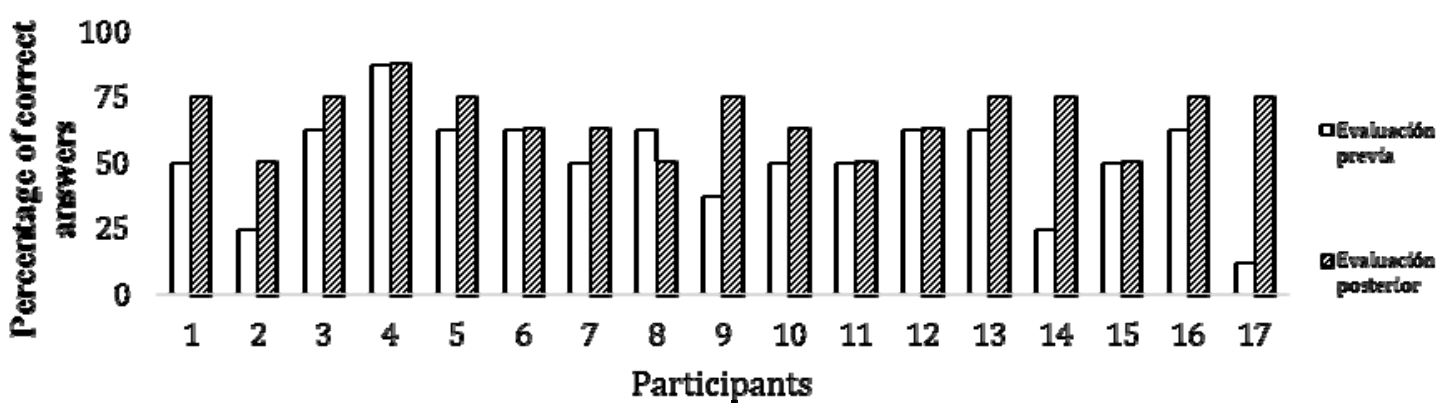

Figure 2. Percentage of correct answers of the participants of the experimental group in the previous and subsequent evaluations

Table 6 shows the percentages of success at each level of achievement in the experimental group, which consists in evaluating the fulfillment of the achievement criterion according to each level of linkage or non-linkage and level of functional aptitude during the intervention. Since the comprehensive learning of mystery and horror stories was conditioned by the instructional procedures organized according to a level of functional aptitude, it was required to verify the percentage of achievement in each level. This assessment of achievement is associated with the learning 
situation in the classroom, which is different from the evaluation that takes place in a more distant period from the moment of learning, as is the case of bimonthly evaluations or at the end of the school year.

Table 6. Percentage of correct answers of each student in achievement evaluations by functional level in the process of the intervention (with individual and group averages, by level)

Note: * Students A4 and A17 only attended the first training session at the respective

\begin{tabular}{lllllll}
\hline Students & $\begin{array}{l}\text { Linked } \\
\text { to object }\end{array}$ & $\begin{array}{l}\text { Linked to } \\
\text { operation }\end{array}$ & $\begin{array}{l}\text { Non-linked } \\
\text { operation }\end{array}$ & $\begin{array}{l}\text { Non-linked } \\
\text { present } \\
\text { situation }\end{array}$ & $\begin{array}{l}\text { to } \\
\text { individual } \\
\text { achievement }\end{array}$ \\
\hline A1 & 100 & 100 & 80 & 60 & $\mathbf{8 5 , 0 0}$ \\
A2 & 91,3 & 100 & 90 & 75 & $\mathbf{8 9 , 0 8}$ \\
A3 & 91,3 & 100 & 100 & 100 & $\mathbf{9 8 , 2 6}$ \\
A4 & 100 & $0 *$ & $0 *$ & 90 & $\mathbf{4 7 , 5 0}$ \\
A5 & 100 & 100 & 70 & 55 & $\mathbf{8 1 , 2 5}$ \\
A6 & 100 & 100 & 50 & 100 & $\mathbf{8 7 , 5 0}$ \\
A7 & 74,7 & 100 & 50 & 90 & $\mathbf{7 8 , 6 8}$ \\
A8 & 100 & 100 & 100 & 55 & $\mathbf{8 8 , 7 5}$ \\
A9 & 83 & 100 & 80 & 50 & $\mathbf{7 8 , 2 5}$ \\
A10 & 91,3 & 100 & 100 & 100 & $\mathbf{9 8 , 2 6}$ \\
A11 & 91,3 & 100 & 70 & 70 & $\mathbf{8 2 , 8 3}$ \\
A12 & 91,3 & 100 & 100 & 70 & $\mathbf{9 0 , 3 3}$ \\
A13 & 100 & 100 & 100 & 60 & $\mathbf{9 0 , 0 0}$ \\
A14 & 91,3 & 100 & 100 & 100 & $\mathbf{9 8 , 2 6}$ \\
A15 & 91,3 & 100 & 100 & 70 & $\mathbf{9 0 , 3 3}$ \\
A16 & 100 & 100 & 100 & 100 & $\mathbf{1 0 0 , 0 0}$ \\
A17 & 91,3 & 100 & $0 *$ & $0 *$ & $\mathbf{4 7 , 8 3}$ \\
\hline \% of group & $\mathbf{9 3 . 4 2 \%}$ & $\mathbf{9 4 . 1 2 \%}$ & $\mathbf{7 5 . 8 8 \%}$ & $\mathbf{7 3 . 2 3 \%}$ & $\mathbf{8 4 . 1 6 \%}$ \\
achievement & & & & & \\
\hline
\end{tabular}

Achievement level, therefore they did not do the achievement evaluation in the second session.

\section{Discussion}

Based on the findings, students who were already in their first year of secondary school and those who had low performance levels in comprehension of narrative texts, specifically in reading stories of mystery and horror, corresponding to the sixth grade of primary school, improved significantly after an intervention focused on the learning process and in correspondence with a level of functional aptitude and achievement depending on their proposed linkage and non-linkage.

1. In the first instance it should be noted that the low average achievement in the reading of two narrative texts of both groups in the pre-test, and the low average in the post test obtained by the comparison group, coincide with the poor results of the achievement in reading comprehension of basic education students in Mexico. Similar performance has been reported by different studies both nationally and at the state level of Morelos (Bazán, Barrera, \& Vega, 2013; Díaz, 2006, INEE, 2017; Ruíz, 2012; Sánchez \& Andrade, 2013). These lower level results of reading comprehension also appear in students who start university studies in Mexico, as shown by the data with undergraduate students reported by Ángel-Gonzalez, et al. (2016), who found that only 1.4\% reached a high level of comprehension, while $75 \%$ reached a regular or medium level and $24 \%$ of students had low levels of comprehension.

Therefore, the intervention reported in this study takes relevance not only in the creation of knowledge, but also in the possibility of deriving strategies for the functional development of reader and writer behavior in primary school, since the reading of mystery and horror stories has been considered an important curricular topic in Mexico. From 2011 to 2017 it used to be a curricular topic in the 6th grade of primary school (SEP, 2011) and in the 
curricular proposal for compulsory education of 2016. It is also included in the first grade of secondary school, in the formative field Language and Communication, axis of literature (SEP, 2016, p.72).

This change in the curricular structure and the change of the topic of mystery and horror stories from the 6th grade to the 1st grade of secondary school, may be associated with the low performance of Mexican students in the comprehension of narrative texts upon leaving elementary school, given that in secondary school, literary texts of greater complexity are studied. However, the data from this study shows that with planning and instruction that develop situations and experiences of functionally more complex interactions and based on increasingly complex criteria of achievement, students who initially had low performance in evaluation of curricular achievement, manage to increase their execution in these reading tasks.

2. To improve reading comprehension in basic education students, real conditions of comprehensive learning should be generated, while focusing training on functional interaction according to different levels of complexity, and developing competent readers. To this effect, it must be emphasised: the importance of the didactic discourse and the structural planning of the learning centered in the interaction and in the establishment of the criteria of achievement by functional aptitude; as well as in the identification in the classroom of the learning interaction and the level of functional aptitude in which such interactions are established.

This study was to develop and apply an intervention based on the structural planning model proposed by Ribes (2008) and the learning process based on competencies and corresponding with the criteria of functional aptitude and achievements. The data of the evaluation in the intervention process shows, in terms of group performance, high percentages (93 and 94\%) in the achievement of more elementary skills levels (linked to the object and linked to operation), and then there is a decrease in the percentage of successes in the two following achievements, $76 \%$ in the achievement of the non-linked operation and $73 \%$ in the non-linked present situation achievement.

Although high percentages of achievement were obtained (between 73 and 100\%), there is a decrease in the performance of students as functional complexity increases in reading comprehension. This decrease in performance in reading comprehension while level of functional complexity of the interactions between the reader, text and mediator are increased, has also been reported in other studies conducted under the interbehavioral perspective.

Fuentes and Ribes (2001) in an experimental study with 6th grade students found a greater reading competence in the non-substitute levels and lower percentages in the substitute levels. Cárdenas and Guevara (2013) in an experimental intervention by levels of functional development with students of 1 st grade of secondary found that in respect of comprehension of Spanish and Natural Sciences texts, although the students achieved high performances, there was a decrease in the substitute levels. Likewise, Velarde and Bazán (2017) reported that, after an intervention according to levels of functional disengagement and levels of achievement in 6th grade students of rural context in three thematic contents of a curricular unit on reading poems, in general, student achievement decreased in more complex levels of achievement: Non-linked to present situation and / or Non-linked to a specific situation. However, the general percentage of correct answers in all levels of achievement fluctuated between 60 and 100\%.

Despite indications of a decrease in reading comprehension with Mexican students in the transition stage between primary and secondary education, as the complexity of achievement increases, experimental interventions with the interbehavioral approach have shown improvements in the comprehension of curriculum-aligned texts (Bazán, Martinez, \& Trejo, 2009, Cárdenas \& Guevara, 2013; Fuentes \& Ribes, 2001, Velarde \& Bazán, 2017), as the results of this study also show. Likewise, the data of this study showed that 15 of the 17 students reached a total average between 79 and $100 \%$ of correct answers in the four levels of competence achievement.

Obviously the ideal is that in classroom practice, to move from a simpler to a more complex thematic unit, students should show $100 \%$ achievement in that unit. However, unlike experimental situations, it is more difficult to control variables and situations that may affect the intervention both in the type of instruction (expository stage) and in situations of evaluation of what has been learned (active stage). For example, in this study, two students obtained an overall average of $48 \%$ of successes in the four achievements, but these had scored zero in two achievements due to absences in the second part of the teaching sessions, at the time when the application or evaluation of achievement by each level was carried out.

3. Another aspect to be considered from the results of this study is that the achievements corresponding to non-linked to present situation (the highest of the four achievements considered in this study), are very satisfactory in seven of the seventeen students (between 90 and 100\% compliance criteria). Also, nine students reached between 50 and $70 \%$ of successes in the achievement of the present situation and only one student failed to meet the established criteria. 
These data show evidence that the type of achievement depends on the directed mediation of the training interaction and that the reactive contact would have a facilitating effect of a historical nature (Ribes et al., 2014). In this process, the teaching corresponds to an expository stage and the evaluation of the achievement would be an active stage (or test).

Similar studies have shown higher reading comprehension rates in learning situations in reading-writing (reading or reading-writing) linguistic modes, and that better results are obtained in the substitution and referential substitution levels, contrasted with the substitute non-referential level (Cárdenas \& Guevara, 2013; Tamayo \& Pulido, 2015; Velarde \& Bazán, 2017).

4. In the learning interaction in the classroom when developing reading skills, unlike studies in controlled experimental environments, the object of knowledge can be presented simultaneously in the oral (discursive), written or audiovisual. Therefore teaching relationships can also include several linguistic modes simultaneously, for example, listening-speaking, reading-writing, reading-speaking, listening and observing - writing and speaking, etc., also establishing different modes of mediation in the same classroom even in the same subject.

Likewise, the actions suggested by the model of Ribes (2008) to structure those education conditions facilitating the acquisition and development of reading comprehension, are only guidelines to exemplify the organization of interactions during the learning process, such as, recognizing, executing, selecting, imagining, theorizing.

Both in planning and in instructional development, the teacher can include various activities that correspond to a certain level of functional aptitude that is sought been developed in the learner. Taking as an example the actions of the student that Ribes suggests in the didactic interaction that corresponds functionally to the level of substitute aptitude referential, grouped in the term imagining; it does not mean that the education discourse is specific to the student only imagining, but also, the student may be interpreting, exemplifying or relating situations, or arguing, as part of a directed mediation of this interaction in correspondence with the achievement criterion implied in the non-linkage from present situation.

\section{Scope and Limitations}

Inter-behavioral approach contributed to more complex literacy learning opportunities and promotes better opportunities for teaching and learning in the classroom (Bazán, Martinez, \& Trejo, 2009; Jensen, Pérez-Martínez, \& Aguilar-Escobar , 2015; Verlade \& Bazán, 2017). As pointed out by Mattarima and Hamdam (2011), learning-centered approaches provide useful instructions to greatly involve students and have great power to obtain rapid and significant progress and high achievement of students in the teaching and learning process.

Precisely, the interbehavioral intervention for learning in school setting is focused on the nature of the interactions and not only oriented to one of its elements: teacher/mediator or student/mediated or content about what is taught and learned.

Although currently is still a very reduced vision of what behavior analysis is in education and its possible applications (Zhao, 2015), the results of this research are in full agreement with the four foundations, pointed out by Bijou (1970). Those are still in force today and are about what the small minority of psychologists (behavioral analysts) have to offer to education:

1. Concepts and principles derived from experimental research and/or conceptual logical analysis, shifted away from of mentalist and causalist conceptions about learning and academic achievement and with respect to education in general;

2. Methodologies for the generation and application of knowledge in various educational processes, including teaching practices;

3. Research designs that describe the individual changes in the child (or learner) instead of inferring their performance from the group means, and

4. A philosophy of science that emphasizes the interactive and identifiable nature of learning as individual behavior, and its determining conditions.

The behavior analysis significantly impacted education in the 20th century with many procedures to improve behavior, management, and teaching; in the same way, education in the twenty-first century is facing with other goals and problems that the behavioral analysis can also address, especially the need to broaden the focus from knowledge acquisition to a real global application, communication and problem solving (Johnson, 2015). It also offers valuable elements for community education and can generate better opportunities for classroom learning, behavioral management and classroom climate. As Twyman and Heward (2018) have also stated, the current tools and applications of behavioral analysis in education have contributed to the increase of active student learning with 
the instructional content planned and implemented by the teacher, focusing on the development of skills and competent practice.

Thus, behaviorists can contribute with instructional models that probabilize environments and conditions for a creative, varied and effective learning in a wide range of disciplinary and life domains (Irigoyen, Acuña, \& Jiménez, 2017; Ribes, 2008), but, these behavioral analysts will have to guide their effective educational methodologies to the necessities and characteristics of conventional education (Kieta, Cihon, \& Abdel-Jalil, 2018) and improve the use of language that allows a more precise, meaningful and more friendly understanding of the communications of their findings in specialized journals, especially in behavioral analysis journals (Diller, Salters-Pedneault, \& Gallagher, 2014).

On the other hand, there are two main limitations of this study. The first is not having included situations of learning with activities of theorization, relationships and consequences, as well as the specification of the achievement non-linked to the concrete situation (Ribes, 2008), which correspond to the non-referential substitute functional level (Ribes and López, 1985). This fact is fundamental to compare the differential effect of the levels of functional training on levels of achievement, especially to compare the achievement non-linked to present situation and non-linked to concrete situation, in reading comprehension.

The second limitation has to do with the fact of not reaching $100 \%$ achievement in all students, to sequentially move from the simplest to the most complex type of achievement. In this study a minimum of $70 \%$ achievement was allowed as a criterion to move from one level to another in instruction or functional mediation, but ideally all students should have achieved $100 \%$ of the achievement criteria to develop their learning transiting for each functional level of instructional arrangement, especially in situations that correspond with selectional interactions, substitutive referential and non-referential substitute.

Future studies in reading comprehension with curricular units and in conditions of teaching in the classroom, will have to take into account these limitations.

\section{References}

Ángel-González, M. et al. (2016). Interbehaviorism Evaluation of Precurrent Repertoires and Reading Comprehension in College Students. Creative Education, 7, 2389-2402. https://doi.org/10.4236/ce.2016.716230

Arroyo, R., Canales, C., Morales, G., Silva, H., \& Carpio, C., (2007). A research program for the functional analysis of reading adjustment. Acta Colombiana de Psicología, 10(2), 31-39.

Arroyo, R., Morales, G., Pichardo, A., Canales, C., Silva, H., \& Carpio, C. (2005). How do you learn to understand?: Functional analysis of history with references. In C. Carpio y J. J. Irigoyen (Eds.), Psicología y Educación: Aportaciones desde la teoría de la conducta (pp. 89-127). México: UNAM.

Bazán, A. (2013). A model of planning and functional structuring of learning criterion situations in the subject of Spanish. In A. Bazán y D. Castellanos (Coords.), La Psicología en la educación. Contextos de aprendizaje e investigación (pp. 55-76). México: Plaza \& Valdez.

Bazán, A., Barrera, D., \& Vega, N. (2013). Construct validation of reading and text production competences in the beginning of the educational reform in the Mexican Elementary School. REICE. Revista Iberoamaricana sobre Calidad, Eficacia y Cambio en Educación, 11(4), 61-76.

Bazán, A., Martínez, X. V., \& Trejo, M. (2009). Analysis of interactions in first grade Spanish classes. Revista Interamericana de Psicología, 43(1), 466-478.

Bijou, S. W. (1970). What psychology has to offer education now. Journal of Applied Behavior Analysis, 3(1), 65-71. https://doi.org/10.1901/jaba.1970.3-65

Cárdenas, K., \& Guevara, Y. (2013). Reading comprehension in junior high school students. an intervention by functional levels. Journal of Behavior, Health \& Social Issues, 5(1), 67-83. https://doi.org/10.5460/jbhsi.v5.1.38727

Carpio, C., Pacheco, V., Flores, C., \& Canales, C. (2000). The behavioral nature of comprehension. Revista Sonorense de Psicología, 14(1 y 2), 1-10.

Díaz, Á. (2006). The massive tests analysis of their technical differences. Revista Mexicana de Investigación Educativa, 11(29), 583-615. 
Diller, J. W., Salters-Pedneault, K., \& Gallagher, A. R. (2014). Effective dissemination requires effective talk: a comparison of behavior-analytic journals. Behavior Analysis in Practice, 7(2), $103-106$. https://doi.org/10.1007/s40617-014-0020-5

Fuentes, M. T., \& Ribes, E. (2001). A functional analysis of reading comprehension as a behavioral interaction. Revista Latina de Pensamiento y Lenguaje, 9, 181-212.

Guevara, Y., Cárdenas, K., \& Reyes, V. (2015). Levels of reading comprehension in high school students. A comparison by topic. Actualidades en $\quad$ Psicología, 29(118), https://doi.org/10.15517/ap.v29i118.14619

INEE, National Institute for the Evaluation of Education (2017). Results report PLANEA 2015. The learning of sixth grade students of primary and third year of high school in Mexico. Language and Communication and Mathematics. México: INEE.

Irigoyen, J. J., Acuña, K. F., \& Jiménez, M. Y. (2013). Reading comprehension and assessment at school. Revista Mexicana de Investigación en Psicología, 5(1), 56-70.

Jensen, B., Pérez Martínez, M. G., \& Aguilar Escobar, A. (2015). Framing and assessing classroom opportunity to learn: The case of Mexico. Assessment in Education: Principles, Policy \& Practice, 23(1), 149-172. https://doi.org/10.1080/0969594X.2015.1111192

Johnson, K. (2015). Behavioral Education in the 21st Century. Journal of Organizational Behavior Management, 35(1-2), 135-150. https://doi.org/10.1080/01608061.2015.1036152

Kantor, J. R., \& Smith, N. W. (1975). The science of psychology: An interbehavioral Survey. Chicago: Principia Press.

Kantor, J. R. (1983). Meanings as events and as constructions in psychology and linguistics. The Psychological Record, 33(3), 433-440. J. R. Kantor as “Observer”.

Keenan, J. M., Betjemann, R. S., \& Olson, R. K. (2008). Reading comprehension tests vary in the skills they assess: Differential dependence on decoding and oral comprehension. Scientific Studies of Reading, 12(3), 281-300. https://doi.org/10.1080/10888430802132279

Kieta, A. R., Cihon, T. M., \& Abdel-Jalil, A. (2018). Problem Solving from a Behavioral Perspective: Implications for Behavior Analysts and Educators. Journal of Behavioral Education, 1-26. https://doi.org/10.1007/s10864-018-9296-9

Mattarima, K., \& Hamdam, A. R. (2011). Understanding students' learning strategies as an input context to design English classroom activities. International Journal of Psychological Studies, 3(2), 238-248. https://doi.org/10.5539/ijps.v3n2p238

Moreno, R. I., Bazán, A., Pacheco, V., \& Irigoyen, J. J. (2017). Planning functional Spanish teaching in last semester students from a normal school. Enseñanza e Investigación en Psicología, 22(1), 1-14.

Pearson, P. D., \& Cervetti, G. N. (2017). The roots of reading comprehension instruction. In S. E. Israel (Ed.), Handbook of research on reading comprehension, 2nd Edition (pp. 12-56). New York, NY: The Guilford Press.

Ribes, E. (1990). General Psychology. México: Trillas.

Ribes, E. (2008). Basic education, psychological development and competencies planning. Revista Mexicana de Psicología, 25(2), 193-207.

Ribes, E. (2011). The concept of competence: its relevance to psychological development and education. Bordón, $63(1), 33-45$.

Ribes, E., \& López, F. (1985). Behavioral Theory. Parametric and Field Analysis. México: Trillas.

Ribes, E., Ibáñez, C., \& Pérez, R. (2014). A methodological proposal for the experimental analysis of comprehensive learning. Revista Mexicana de Psicología, 31(2), 100-110.

Rodríguez-Ramírez, M., \& Rodríguez-Pérez, M. (2014). Structuring of learning situations from the interbehavioral perspective. Summary in extensive, XV National Colloquium of Teacher Training, September 4 and 5, Morelia, Michoacán.

Ruíz, G. (2012). The Comprehensive Reform of Basic Education at the elementary school level: challenges for teacher training. Revista Electrónica Interuniversitaria de Formación del Profesorado, 15(1), 51-60. 
Ryle, G. (2005). translation to Spanish). The concept of mind. Barcelona: Paidós

Sánchez, A., \& Andrade, E. (2013). Learning in the sixth grade of primary school in Mexico. Report on the results of Excale 06, application 2009. Spanish, Mathematics, Natural Sciences and Civic Education. México: INEE.

Secretaria de Educación Pública, SEP (2011). Syllabus. Agreement number 592. Available on: http://basica.sep.gob.mx/ACUERDO\%20592web.pdf

Secretaria de Educación Pública, SEP (2016). Curricular proposal for compulsory education 2016. México: SEP

Tamayo, J., \& Pulido, L. (2015). Comprehensive learning: enabling effect in complementary linguistic modes. Journal of Behavior Health \& Social Issues, 7(2), 57-66. https://doi.org/10.5460/jbhsi.v7.2.47718

Twyman, J. S., \& Heward, W. L. (2018). How to improve student learning in every classroom now. International Journal of Educational Research, 87, 78-90. https://doi.org/10.1016/j.ijer.2016.05.007

Velarde, N. \& Bazán, A. (2017). Program of functional instruction in reading comprehension of poems in elementary school students. Interacciones. Revista de Avances en Psicología, 3(3), 121-130. https://doi.org/10.24016/2017.v3n3.70

Wittgeinstein, L. (1997, translation to Spanish). Remarks on the philosophy of Psychology. Volume II. México: UNAM

Zhao, L. (2015). An Analysis of the Learners' Factors in Second Language Teaching and Learning. International Journal of Psychological Studies, 7(4), 130-135. https://doi.org/10.5539/ijps.v7n4p130

Appendix 1

Examples of teaching and learning activities separated by level of achievement

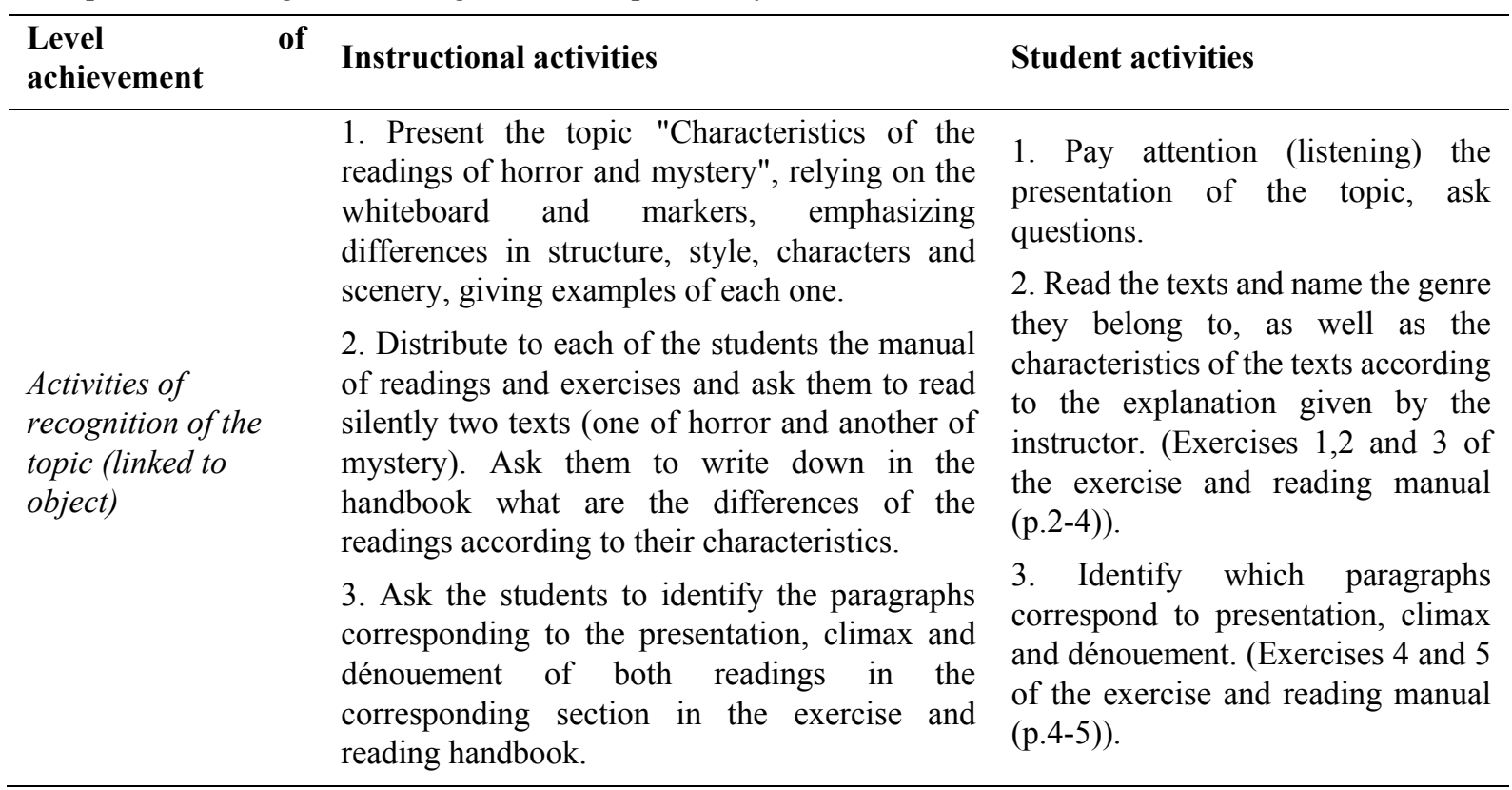


Operation activities on the referent (linked to operation)
1. Ask students to read the following text of horror from their manual of readings and exercises, in which the characteristics of the protagonists will have to be highlighted in red and the characteristics of the antagonists in blue.

2. Ask the students to describe in the following table of their manual the protagonists and antagonists of the readings of horror and mystery. They can use physical or emotional description of these.

3. Ask the students to answer the questions in their handbook about the characteristics of the horror and mystery readings.

1. Read the horror text of the reading and exercises handbook and highlight the characteristics of the protagonists in red and the characteristics of the antagonists in blue. (Exercise 6 of the exercise and reading manual (p.5-6)).

2. Describe the protagonists and antagonists of the readings of horror and mystery in the following table of the manual. They can use physical or emotional description. (Exercise 8 of the handbook of exercises and readings (p.6)).

3. Answer the direct questions in the reading and exercise handbook. (Exercise 9 of the exercise and reading manual (p.7)).

1. Present cards sticked on the board with the different characteristics of the horror and mystery texts, which are the same as those found in the readings and exercises handbook. They should be classified in a table depending on

Property selection activities of the referent (non-linked to specific operation) whether they are structural characteristics, style, characters or scene.

After completing the table, the teacher should review, assess and provide feedback to the students, if they correctly classified the characteristics or not.

2. Ask the students to classify in a table of their handbook the examples of structure, style, characters or scenario characteristics.

1. Divide the group into teams and present a reading of horror to change it to mystery reading. They must take into account the previously explained characteristics (structure,

Activities of application and substitution of the referent (non-linked to the present situation) style, characters and scenario). Each member of the team must write the reading version of their team in their readings and exercises handbook.

2. After the teams read aloud to the group their mystery version of the first reading, students are asked to argue in a debate why the reading version of each of the teams is correct or incorrect.
1. Answer the table of characteristics of the mystery and horror stories in the reading and exercises manual. Go in front of the class to classify at least one characteristic in the corresponding box on the whiteboard. (Exercise 10 of the exercise and reading manual (p.7)).

2. Classify the examples of characteristics of horror and mystery readings in the table as appropriate.

(Exercise 11 of the exercise and reading handbook (p.8)).

1. Illustrate how the text of horror would be if it were mystery.

(Exercises 12 and 13 of the readings and exercises handbook (p.9-11)).

2. Argument why the story version of the other team is correctly or incorrectly adapted according to the characteristics of this type of texts.

(Exercise 14 of the readings and exercises handbook (p.12).

\section{Copyrights}

Copyright for this article is retained by the author(s), with first publication rights granted to the journal.

This is an open-access article distributed under the terms and conditions of the Creative Commons Attribution license (http://creativecommons.org/licenses/by/3.0/). 